\title{
DUCEMSERIYA REALÎZMA SOSYALÎST DI ROMANÊN EREBÊ ŞEMO Û HECIYÊ CINDÎ DE
}

\author{
Zülküf ERGÜN*
}

\begin{abstract}
Kurte
Realîzma sosyalîst navê polîtîkaya fermî ya edebiyata Sovyetê ye ku ji salên 1930î heta dawiya Sovyetê li seranserî vî welatî edebiyateke hevşêwe afirandiye. Edebiyata kurdî ya Sovyetê jî di vê maweyê de li ser vê bingehê û di bin karîgeriya vê rêbaza edebî de hatiye berhemanîn ku bi giştî xwe dispêre civaka kurdên êzîdî. Di vê gotarê de sê romanên Erebê Şemo û romana Hewarîyê ya Heciyê Cindî di vê çarçoveyê de tên nirxandin. Lewra Erebê Şemo û Heciyê Cindî wek du nivîskarên pêşeng ên vê edebiyatê di çarçoveya rêbaza ducemseriya realîzma sosyalîst de romanên xwe dikin zemîna berawirdkirina feodalîzm û sosyalîzmê û piştgiriya bicihkirina bernameya damezirandinê ya sosyalîst dikin. Bi vê mebestê di romanên xwe de mijarên zordariya feodalîzmê û rizgarkeriya Şoreşa Bolşevîk, adetên xirab ên feodalîzmê û azadîxwaziya sosyalîzmê, nezaniya serdema feodal û ronakgeriya Sovyetê, paşdemayîna feodalîzmê û pêşketina aboriya sosyalîst berawird dikin û bi vê rêbaza xwe dibin nerîtdanerên edebiyateke yekdeng û yekreng di edebiyata kurdî ya Sovyetê de.
\end{abstract}

Bêjeyên Sereke: Edebiyata Kurdî ya Sovyetê, realîzma sosyalîst, ducemserî, Erebê Şemo, Heciyê Cindî.

\section{EREBÊ ŞEMO VE HECIYÊ CINDÎ'NIN ROMANLARINDA TOPLUMCU GERÇEKÇILIIĞIN İKI KUTUPLULUĞU}

\section{Öz}

Toplumcu gerçekçilik Sovyet edebiyatının resmi edebiyat politikasının adı olup 1930'lu yıllardan Sovyetler Birliğinin dağılmasına kadar bu ülkede homojen bir edebiyatın oluşmasına sebep olmuştur. Genel olarak Yezidi Kürt toplumuna dayanan Sovyet Kürt edebiyatı da bu süre zarfında bu yöntemin etkisi altında üretilmiştir. Bu makalede Erebê Şemo'nun üç romanı ve Heciyê Cindî’nin Hewarî romanı bu çerçevede incelenmiştir. Erebê Şemo ve Heciyê Cindî Sovyet Kürt edebiyatının iki öncü yazarı olarak toplumcu gerçekçiliğin iki-kutupluluk yöntemine dayanarak romanlarını feodalizm ve sosyalizm karşılaştırması çerşevesinde kurgulamış ve sosyalist inşa programının uygulamasına destek vermişlerdir. Bu amaçla romanlarında feodal baskı ile kurtarıcı Bolşevik Devrimi, feodalizmin kötü adetleri ile özgürlükçü sosyalizm, feodal dönemin cehaleti ile Sovyet aydınlaması, feodalizmin geri kalmışlığ ile sosyalist ekonominin ilericiliği konularını karşılaştırıp Sovyet Kürt edebiyatında tek sesli ve tek renkli bir edebi geleneğin kurucuları olmuşlardır.

Makale gönderim tarihi: 03.10.2017, kabul tarihi: 10.11.2017

Doi: $10.26791 /$ sarkiat.341439

* Zanîngeha Mardin Artukluyê, Beşa Makezanista Ziman û Çanda Kurdî, zxweshevi@gmail.com 
Anahtar Kelimeler: Sovyet Kürt edebiyatı, toplumcu gerçekçilik, iki kutupluluk, Erebê Şemo, Heciyê Cindî.

\title{
BIPOLARITY OF SOCIAL REALISM IN EREB SHEMO AND HECIYÊ CINDÎ'S NOVELS
}

\begin{abstract}
Social realism is the name of official literature policy of Soviet Literature that started in 1930s and founded a homogenous literature until the dissolition of Soviet Union. Soviet Kurdish Literature which was mainly dependent to Yezidi Kurdish community, was produced under effects of that policy during that time. In this article we examine three novels by Ereb Shemo and a novel by Heciyê Cindî titled Hewarî from that perspective. Both Ereb Shemo and Heciyê Cindi, as two avantgarde autors of Soviet Kurdish literature relied on bipolar method of Social Realism and fictioned their novels in the framework of comparison of feudalism and socialism and in doing so supported the implementation of socialist founding programme. They became founders of a monophonic and monochromic literacy tradition in Soviet Kurdish Literature comparing subjects like feudal oppression and rescuer Bolshevist Revolution, bad habits of feudalism and liberator socialism, ignorance of feudalism and Soviet enlightenment, backwardness of feudalism and progressivism of Soviet economy
\end{abstract}

Keywords: Soviet Kurdish Literature, social realism, bipolarty, Ereb Shemo, Heciyê Cindî.

\section{Destpêk}

Peywendiya edebiyat û siyasetê yan jî teoriyên edebî û siyasetê di sedsalên nozdeh û bîstî de digihîje asteke bilind. Bi taybetî jî netewetî û marksîzm wek du bizavên mezin ên vê serdemê, edebiyatê wek qadeke damezirandina îdeolojîk derdixin pêş û di bin per û baskên siyaset û îdeolojiyên diyarkirî de araste didinê. Ji ber vê di bin navên ciyawaz de li gelek welatan "edebiyatên neteweyî" û "edebiyatên sosyalîst" tên avakirin. Bêguman edebiyata Sovyetê û teoriya wê ya realîzma sosyalîst jî di encama têkiliyeke weha de peyda dibe û armanc û naveroka wê rasterast ji aliyê kesayetên siyasî ve tê diyarkirin.

Edebiyata kurdî ya Sovyetê jî wek mînakeke biçûk a edebiyata giştî ya Sovyetê di çarçoveya riwangeha siyasî ya rayedarên Sovyetê de tê afirandin û taybetmendiyên realîzma sosyalîst di nav xwe de vedihewîne. Jixwe di wê serdemê de di nav sînorên siyasî yên Sovyetê de mecala peydabûn û belavkirina edebiyateke din jî nebû. Lewra sansureke bihêz a dewletê li ser weşanê hebû û derfetên berhemanîna edebiyateke ciyawaz gelek sînordar bû. Ji ber vê ev edebiyat ji aliyê naverok û forma xwe ve bû deravêteya sîstema çandî û alegoriya îdeolojiya Sovyetê.

Di zemîneke weha de edebiyata kurdî ya Sovyetê bi giştî ji aliyê komeke kurdên êzîdî ve hat berhemanîn ku di encama șerên dûrûdirêj ên împaratoriyên rûsî û osmanî de xwe li rûsan girtibûn. Ji ber vê ev edebiyat xwe dispêre sosyolojiyeke diyar a kurdewarî ku rû û rûçikên komeke etnîk a paşdemayî pê ve diyar e. Lewra ev koma etnîk ji ber ciyawaziya xwe ya dînî her ji mêj ve bi awayekî goșegîr dijiyan û ji aliyê piraniya kurdan ve jî hatibûn perawêzxistin. Ji ber vê di nav wan de tu carî nerîteke nivîskî û çandeke xwendewariyê peyda nebûbû. Vê koma etnîk cara pêşî bi saya Sovyetê derfeta afirandina çand û edebiyateke nivîskî bi dest xist û bûn 
beşeke girîng di danîna bingeha edebiyata nû ya kurdî de. Lewra piştî serxistina Şoreşa Bolşevîk û damezirandina Sovyetê di çarçoveya diyarkirina mafề gelan de mafê pêşvebirina çanda hemû neteweyên nav Sovyetê hatibû pejirandin û li ser vê bingehê bi pêşengiya kadroyên siyasî yên Partiya Komunîst û piştgiriya dezgehên dewletê bingeha çand û edebiyata kurdên Sovyetê hat danîn.

Her di vê çarçoveyê de Erebê Şemo (1898-1978) û Heciyê Cindî (1908-1990) di danîna bingeha edebiyata kurdî ya Sovyetê de wek du pêşengên diyar derdikevin pêş. Erebê Şemo ji bilî ku rêvebiriya dezgehên pêşî yên çand û edebiyata kurdî dike, digel Îsahak Maragûlov dibe danerê alfabeya latînî ya kurdî ku yekem rojname û berhemên edebî yên kurdî li Sovyetê bi vê alfabeyê derdikevin û heta salên çilî jî gelek berhem pê tên weşandin. Herweha Şemo bi nivîsîna yekem roman û wergera edebî ya kurdî di warê edebî de serkêşî dike û wek berpirsiyarê Partiya Komunîst a navçeyên kurdî bi nivîsîna pirtûkên xwe yên mîna Emrê Lenîn, Terîqa Rêvolûsiya Oktobirê û Kolxoz û Kara Wê Ji Gundiyan ra jî (Boyîk, 2004: 29-30) dibe nûnerê herî bihêz ê bernamaya damezirandina sosyalîst di nav kurdan de.

Heciyê Cindî jî wek Erebê Şemo her ji destpêkê ve di damezirandina vê edebiyatê de xwedî cihekî girîng e. Wek pêş̧engê duyem di qonaxa pêşî de serokatiya beşa Yekîtiya Nivîskarên Kurd dike û di amadekirina pirtûkên dersan de beşdarî dike. Piştî qedexekirina alfabeya latînî bi raspartina hikumeta Ermenistanê li ser bingeha tîpên kirîlî alfabeyeke nû ji bo kurdên Sovyetê datîne (Boyîk, 2004: 47) û piştî bidawîhatina serdema Stalîn jî careke din di dezgehên çandî yên kurdî de roleke pêşeng digêre. Bi vî awayî Erebê Şemo û Heciyê Cindî hem ji aliyê têkiliyên xwe yên siyasî hem jî ji aliyê destpêşxeriya xwe ya çandî û edebî ve wek nûnerên tîpîk ên edebiyata Sovyetê li ser hesabê armancên diyar ên dezgehên dewletê edebiyateke pêgîr berhem tînin.

Di vê gotarê de ji bo diyarkirina taybetmendiyên teoriya realîzma sosyalîst, ku rêbaza sereke ya edebiyata kurdî ya Sovyetê ye, em dê pêşî bingeha teorîk a edebiyata Sovyetê vekolin paşê jî em dê di romanên Şivanê Kurmanca, Jiyana Bextewar û Hopo yên Erebê Şemo û Hewarîya Heciyê Cindî de şopên vê têgihîştinê destnîşan bikin. Bêguman dema em vê dikin ne ku em hemû taybetiyên rêbaza realîzma sosyalîst berçav dikin, bêtir em dixwazin bal bikêşin ser ducemseriya feodalizm û sosyalîzmê ku çavkaniya xwe ji jiyan û îdeolojiya kurdên Sovyetê werdigirin û di romanên navborî de jî bi rêya rûdan, karekter, cih û demên dijber de tên berawirdkirin.

\section{Bingeha Teorîk a Edebiyata Sovyetê}

Edebiyata Sovyetê di çarçoveya teoriya realîzma sosyalîst de şaxeke rexneya marksîst û şîroveyeke nû ya rexneya sosyolojîk e ku kesayetên mîna Giambattista Vico (1668-1744), Madame de Stael (1766-1817) û Hippolyte Taine (1828-1893) bingeha wê datînin. Lewra cara pêşî ev kesayet bi awayekî sîstematîk berhemên edebî bi mercên sosyolojîk ve girê didin û têkiliya nivîskar, deqên edebî û xwendevanan di nav tora peywendiyên civakî de berçav dikin. Piştî demekê her di vê çarçoveyê de li ser hizrên Marks (1818-1883) û Engels (1820-1895) bi navê estetîka marksîst bizaveke nû ya rexneyî peyda dibe ku mercên civakî bi nêrîneke nû şîrove dike û di afirandina berhemên edebî de mercên aborî û milmilaneya çînî derdixe pêş. Li gor vê têgihîştinê aborî jêrxana hemû çalakiyên mirovan e û çand, 
dîn, hiqûq, felsefe, huner û edebiyat jî wek serxan ji aliyê jêrxana aborî ve tên diyarkirin.

Digel vê hevbeşiyê, piştî demekê rexneya marksîst bi ser du rewtên sereke yên ortodoksî û para marksîst de dabeş dibe (Şan, 2012: 138) û realîzma sosyalîst a Sovyetê li ser nerîta ortodoksî di çarçoveya hizrên Plehanov (1856-1918), Lenin (1870-1924), Jdanov (1896-1948), Lunaçarskî (1875-1933) û Gorkî (1868-1936) de teşe digire. Teorîdanerên vê rêçikê bi giștî li ser mijarên mîna naverok û ruxsarê, nirxa estetîk û nirxa civakî û bêalîbûn û pêgîriya nivîskar radiwestin û di vê çarçoveyê de hewl didin li dijî edebiyata cîhana kapîtalîst edebiyateke alternatîf berhem bînin. Loma jî di berjewendiya naveroka îdeolojîk û sûda çînî de ciwankariya berhemên edebî paşguh dikin û li hember têgihîştina huner bo hunerê, formalîzm û sembolîzmê; hêz didin têgihiștina huner bo civakê, edebiyateke pêgîr û sadebûnê.

Plehanov wek pêşengê pêşwext ê vê hizrê bi navê estetîka marksîst teoriyeke edebî datîne û vê teoriyê li ser bingeha dîrokî ya mulkiyet, çîn û awayên îdeolojiyan ava dike. Di têgihîştina wî de huner amrazeke zanînê, girêdaneke komelayetî, çekê çînekê, gihandina hişmendiyekê û awêneya komelekê ye (Fréville, 1999: 21). Erka vê estetîkê ne tenê destnîşankirina hizra xweşikiyê ya hunerê ye, di heman demê de derxistina meyla mirovan e ji bo rastî, hezkirin û qenciyê (Fréville, 1999: 24). Ji ber vê jî Plehanov ruxsarê bi naverokê ve girê dide û ruxsarparêziyê wek diyardeyeke netendurist a civakî dibîne ku di rewşên weha de hevahengî di navbera hunermend û navendên civakî de namîne û hunermend bi awayekî rasterast yan nerasterast dikeve bin xizmeta desthilatên serkutker (Plîxanof, 2005: 12). Li gor wî dema ruxsar bikeve pêşiya naverokê edebiyat paşve diçe û di demên weha de hunerên bêsûd ên mîna decadent û futurîzmê peyda dibin (Fréville, 1999: 57). Ji ber vê, meyla sembolîzmê ya van rêbazan bi firkiya hizrî ya wan ve girê dide û sembolîzma wan jî nîşaneya xizaniyê dide zanîn (Plehanov, 1999: 160).

Diyar e, marksîzma ortodoksî di serê sedsala bîstî de bêtir li ser destê pêşengên komunîzma rûsî teşe digire. Bi taybetî bi damezirandina partiyên marksîst re edebiyat bi tevahî ji aliyê kadroyên siyasî ve tê domînekirin û di çarçoveya riwangeha van partiyan de edebiyateke partîzan tê berhemanîn. Lenîn wek pênasekerê yekem ê çemka edebiyata partiyê di gotara xwe ya "Parti Örgütü ve Parti Edebiyatı"yê de (Rêxistina Partiyê û Edebiyata Partiyê), ku di 1905an de weşandiye, li dijî wê yekê derdikeve ku edebiyat bibe amraza dewlemendiya takekes û koman û edebiyatê bi doza giştî ya proleteryayê ve girê dide. Li gor wî "divê edebiyat bibe beşek ji doza giştî ya proleteryayê û bibe "çerx û vîdeyeke biçûk" a mekanîzmaya sosyal demokrasiyê ku tenê ji aliyê pêşengên hişmend ên proleteryayê ve tê livandin". Ji ber vê berê xwe dide nivîskaran û dibêje: "Bila bicehimin nivîskarên bêpartî! Bila bicehimin mirovên raser ên edebiyatê!" (MarxEngels-Lenin, 2006: 197) û bi van gotinan di bin navê "edebiyata partiyê" de edebiyata takekesî bi tevahî red dike. Her di vê çarçoveyê de Lenîn doza wê yekê dike ku hemû rojname bibin organên partiyê û navendên weşanê, pirtûk, pirtûkxane û dezgehên bi vî awayî jî bikevin bin kontrola partiyê (Marx-Engels-Lenin, 2006:198). Ev têgihîştina hişk û tund dibe sedem ku piştî serkeftina Şoreşa Bolşevîk edebiyateke fermî ya desthilata komunîst bê avakirin û ev edebiyat ji aliyê dezgehên dewletê ve bê arastekirin. 
Li ser vê bingehê, piştî Şoreşa Bolşevîk ji bo afirandina edebiyatekê ku di bin xizmeta îdeolojiya çîna karker de be li ser destê Bogdanovê pêşengê proletkultê hewla afirandina çand û hunereke karkeran tê dayîn û ev ji aliyê Rêvebiriya Perwerdeya Gel ve li çar aliyên Sovyetê tê belavkirin. Bogdanov, proletkultê wek dezgeha çandî ya Sovyetê li tenişt partî û sendîkayan ji bo geşbûna dîktatoriya proleteryayê wek pêwîstiyekê dibîne (Kurtuluş, 1996: 20-25) û pêgîrbûna xwe ji bo çîna proleter diyar dike. Digel vê pêgîriyê, pêşengên proletkultê ji ber ku doza xweseriya çandî dikin tevî komên edebî yên LEF (Bereya Hunera Çep) û RAPPê (Yekîtiya Nivîskarên Proleter) ji aliyê desthilata Sovyetê ve tên jinavbirin (İdil, 1983: 25-26) û Komîteya Navendî ya Partiya Komunîst biryar dide ku rasterast naveroka xebatên komên nivîskaran ji aliyê desthilatê ve bê diyarkirin û rêbertiya edebiyatê bikeve destê çîna karker (Kurtuluş, 1996: 136). Ev milmilaneyên li ser xweseriya edebiyat û hunerê di 1932yan de li ser destê Stalîn (1879-1953) bi dawî dibe. Ji ber vê hemû komên edebî tên belavkirin û azadiya rêjeyî ya berê namîne (Oktay, 2008: 107). Stalîn bi gotina "nivîskar mîmarên ruhê mirovan in" (Oktay, 2008: 86) erkeke siyasî dide ser milên nivîskaran û di encama vê de jî di sala 1934an de di kongreya pêşî ya Yekîtiya Nivîskarên Sovyetê de bi navê realîzma sosyalîst edebiyateke fermî tê ragihandin.

Bêguman kongreya Yekîtiya Nivîskarên Sovyetê ya 1934an yekem pêngav e ji bo teorîzekirina realîzma sosyalîst ku Lunaçarskî, Jdanov û Gorkî wek damezirîner û pêşengên vê reçikê derdikevin pêş̧. Lewra kesayetên navborî ne tenê bi hizrên xwe, bi erk û berpirsiyariyên xwe yên fermî jî di arastekirina edebiyatê de beşdarî dikin û dibin nûnerên berbiçav ên teoriya realîzma sosyalîst û edebiyata partiyê. Lunaçarskî wek nûnerekî diyar ê rewta ortodoksî ya rexneya marksîst û berpirsê Komîteya Gel a Karê Perwerdeyê di Hikumeta Sovyetê de, derbarê rexneya marksîst de diyar dike ku ev rexne bi taybetiya xwe ya sosyolojîk ji rexneyên din cuda dibe û xwe dispêre sosyolojiya zanistî ya Marx û Lenîn. Li gor wî berhema hunerî ya ku têkildarî hişmendiya çînekê yan jî xwedî karektereke civakî ye, ji aliyê naverokê ve tê diyarkirin û naverok hertim dikeve pêşiya ruxsarê. Ji ber vê jî erka pêşî ya rexnegirê markîst di vekolîna naveroka berhemên edebî û derxistina cewhera wan a civakî de dibîne. Di nêrîna Lunaçarskî de rola ruxsarê tenê ew e ku hêza vegêrana naveroka berhemê zêde bike û bi vê rêkê karîgerî û telqîna wê ya li ser xwîneran zêde bike (Lunaçarski, 2000: 14-16). Loma jî ruxsarê bi naverokê ve girê dide û wek regezeke serbixwe berê xwe nade ruxsarê (Lunaçarski, 2000: 21).

Lunaçarskî ji ber ku marksîzmê wek bernameyeke damezirandinê dibîne (Lunaçarski, 2000: 18), piştî Şoreşê dixwaze edebiyatê jî bike qadeke cîbicîkirina vê bernameyê. Loma doza wê yekê dike ku edebiyat êdî dev ji nîşandana xetên giștî yên jiyanê û karekterên bêbiryar berde û bi hilgirtina roleke siyasî, rewiştî û civakî kar li ser pêvajoya damezirandinê bike (Lunaçarski, 2000: 13). Navborî bi mebesta gihîştina vê armancê her tiştê xizmeta serkeftina çîna proleter bike baş û her tiştê ziyan bide vê dozê jî xirab dibîne (Lunaçarski, 2000: 18). Ji ber vê jî hunerê wek çekeke bihêz a ajîtasyonê dide destê Şoreşê (Lunaçarski, 2000: 43) û li hember "dîmenên biyanî û dijminkarane yên qada edebiyatê" jî erka "sansura marksîst" dispêre dezgehên fermî yên Sovyetê (Lunaçarski, 2000: 20). Di çarçoveya vê têgihîştinê de Lunaçarskî di kongreya 1934an de dema derbarê realîzma sosyalîst de diaxive behsa temayên taybet bi realîzma sosyalîst dike ku peywendiya wan bi fonksiyona bingehîn a jiyanê re heye û ji bo avakirina jiyaneke sosyalîst pêwîst in 
(Oktay, 2008: 112). Bi vî awayî aşkera behsa edebiyateke sîparîşkirî dike ku bi mijarên xwe di çarçoveya berjewendiya dewletê de be.

Jdanov wek teorîsyenê herî tîpîk ê realîzma sosyalîst û endamê Komîteya Merkezî ya Partiyê, di Kongreya Nivîskarên Sovyetê de li hember sîstema kapîtalîst edebiyatê beşek ji bernameya damezirandinê ya sosyalîst dide zanîn (Jdanov, 1996: 13) û serkeftina edebiyata Sovyetê jî bi serkeftina damezirandina sosyalîst ve girê dide. Herwek sîstema giştî ya Sovyetê erka edebiyata Sovyetê jî jinavbirina mêtinkariya karker û çewsandiyan, têkoşîna serxistina sosyalîzmê, berevaniya wekheviya mafên kedkaran, doza wekheviya jin û mêran û dijayetiya her cure nezanîn, mîstîsîzm û bîrhişkiyê dizane (Jdanov, 1996: 15). Jdanov bi vê naverokê edebiyata Sovyetê wek alternatîfa edebiyata cîhana burjuvayê derdixe pêş ku bi dîtina wî ev edebiyat di nav mîstîsîzm û pornografiyê de têkçûye û nivîskarên wê jî wek "kesên qelemfiroş mijûlî dizî, ajantî, qundetî û beredayîtiyê" ne (Jdanov, 1996: 16). Li hember vê, edebiyata Sovyetê wek edebiyateke pak û rewiştparêz dide zanîn ku kereste, mijar, îmaj, ziman û şêwaza xwe ji jiyan û azmûna xelkê, ji azmûnên kolxozan û ji çalakiyên afirîner ên her çar aliyên welat werdigire (Jdanov, 1996: 17).

Jdanov li dor mijara rêbaza realîzma sosyalîst çarçoveya giştî ya edebiyata Sovyetê jî destnîşan dike. Li gor wî divê edebiyata Sovyetê li ser geşbînî, şewq û qehremaniyê bê avakirin û lehengên xwe yên sereke jî ji karkerên jin û mêr, kolxozvanên jin û mêr, endamên Partiyê, rêvebir, endazyar û ji komunîstên ciwan (komsomol) hilbijêre ku bi dil $\hat{u}$ can ji bo damezirandina "jiyana nû" $\hat{u}$ "damezirandina sosyalîst" kar dikin (Jdanov, 1996: 17). Ev jî nîşan dide ku edebiyata Sovyetê bi afirandina van tîpên erênî di riwangeha pêşengên realîzma sosyalîst de berê xwe dide romantîzmekê. Lewra her bernameyeke damezirandinê bivê nevê xwe dispêre cure romantîzmekê û di nav xwe de îdealîzmekê vedihewîne. Jdanov jî ji bo bicihanîna vê bernameyê têra xwe bi realîzmê nayîne û têkiliyek di navbera realîzma sosyalîst û romantîzmê de datîne. Ji ber vê di şûna romantîzma kevin a ku bi dîtina wî li ser cîhaneke nebûyî û qehremanên xeyalî hatiye avakirin, romantîzma şoreşgêr datîne (Jdanov, 1996: 18) û wê dike temamkerê realîzmê. Lewra Jdanov ji bo rizgarkirina hemû kedkar û çewsandiyan û pêkanîna civakeke wekhev û dadperwerane romantîzma şoreşgêr a alîgir pêwîst dizane û têra xwe bi realîzma rût a bêalî nayîne.

Jdanov di axaftina xwe ya kongreyê de gelek caran koma nivîskaran wek "artêşa nivîskaran" û taybetmendiyên ruxsarî yên edebiyatê jî wek "çek" pênase dike û bi awayekî aşkera edebiyatê bi peyv û termên leşkerî rengrêj dike. Ji ber vê jî nivîskarên Sovyetê li dijî edebiyata cîhana kapîtalîst wek bergirîkar û di bicihkirina bernameya damezirandina sosyalîst de jî bi gotina Stalîn wek mîmarê ruhê mirovan dide zanîn. Loma jî di dawiya axaftina xwe de ji nivîskarên Sovyetê dixwaze: "Bi hostatiyeke serkeftî û bi naverokeke îdeolojîk û hunerî berhemên bilind bînin holê! Bi ruhekî sosyalîst bibin rêkxerê herî çalak di pêgihandina gel de û di têkoşîna damezirandina civakeke bêçîn û sosyalîst de di rêzên herî pêş de cih bigirin" (Jdanov, 1996: 20). Ev nîşan dide Jdonov çi wek çek û mertaleke têkoşîna derekî çi jî wek bernameya damezirandina sosyalîst a navxweyî be bi çavê "çekekî karîger" li edebiyatê dinêre û edebiyatê wek qadek ji qadên têkoşîn û dijayetiya kapîtalîzmê dizane. 
Maksîm Gorkî wek damezirînerê sereke yê realîzma sosyalîst di kongreya 1934an de pêşî rexne li hizra azadiya hunerê û keyfîbûna hizra afirîneriyê ya edebiyata sedsala bîstî ya Ewrûpayê digire û vê hizrê sedema wê yekê dizane ku edebiyat ji çarçoveya jiyana çînî û siyaseta civakî hatiye derxistin. Bi dîtina wî, ev têgihîştin bûye sedem ku "gelek edebiyatvan çembera xwe ya çavdêriya rastiyan teng bikin, ji jiyanê dabirin, di nav tenêtiya xwe ya ruhî de bên zindanîkirin û bi rêya azadiya hizir di nav kûrahiyên xwe de bidin dû hizra xwenasîna bêencam”. Li gor wî mirov çi qas bi awayekî cuda behsa xwe bike bila bike yekeyeke civakî ye û takekesparêziya ku vediguhere egosantrîzmê ji bilî mirovên beredayî tu tiştekî nikare berhem bîne (Gorki, 2009: 109).

Gorkî di axaftina xwe de pêşwazî li Partiya Komunîst û Lenînîst a Yekîtiya Sovyetê dike ku dawî li kapîtalîzma Rûsyaya Çarîtiyê aniye, desthilat radestî karker û gundiyan kiriye û civakeke bêçîn ava kiriye. Loma jî ji edebiyatvanên Sovyetê dixwaze di çarçoveya vê riwangehê de çalakiyên xwe di ber çavan re derbas bikin (Gorki, 2009: 115) û di berhemên xwe de qehremanên weha hilbijêrin ku ji aliyê pêvajoya xebatê ve hatibin teşedan û xebat gihandibin asta hunerê (Gorki, 2009: 116). Gorkî li ser nerîta marksîst; afirandin, berhemanîn û aboriyê kêşeya sereke ya realîzma sosyalîst dide zanîn û edebiyatê jî wek şêweya estetîzekirina vê armancê derdixe pêş. Li gor wî di rêçika realîzma sosyalîst de hebûn; çalakî û afirînerî ye û armanca wê jî têkbirina hêzên siruştî, dabînkirina jiyaneke dirêj û tendurist û avakirina dinyayeke biewle ye ku hemû mirov bikarin tê de wek malbetekê bijîn (Gorki, 2009: 123).

Gorkî ji bo gihîştina van armancan ji baskê edebî yê rêvebiriya Partiyê dixwaze bi awayekî cîdî kar ji bo wê yekê bikin da bikarin edebiyatê ji bin karîgeriya îdeolojiya "burjuvaziya biçûk a kurtêlxur" pak bikin û di şûna wan de edebiyatvanên partîzan pêbigihînin ku bibin mamosteyên rêkxistina enerjiya têkoşîna azadiya çîna karker. Li gor wî bi pêgihîştina vê nifşa nû dê edebiyata Sovyetê di nav tevkariyeke kolektîf de wek çekê bihêz ê çanda sosyalîst bê rêkxistin (Gorki, 2009: 121-122) û bigihîje armanca xwe. Jixwe Gorkî armanca damezirandina Yekîtiya Nivîskaran di vê yekê de dibîne ku ev rêxistin bikare rêvebiriya "artêşa nivîskaran" bike, wan rêk bixe, hêza wan li gor xebatên curbicur belav bike û wan hînî wê yekê bike ku bikarin bi daneyên raborî û îro bixebitin (Gorki, 2009: 124).

Diyar e, damezirînerên realîzma sosyalîst, hewl didin edebiyata Sovyetê bikin beşek ji bernameya damezirandinê ya îdeolojiya sosyalîst û herwekî cîhana derekî, di cîhana vêkxistî (fîktîf) de jî li hember feodalîzm û kapîtalîzmê ducemseriyekê pêk bînin. Di çarçoveya vê têgihîştinê de edebiyata Sovyetê di forma berawirdkirin û ducemseriyekê de ji bo rastdêrana cemsera Sovyetê û pûçkirina cemsera neyarên Sovyetê tê rêkxistin û li hember çand û edebiyata cîhana kapîtalîst a burjuvayî û bermayiyên civaka feodal, nûnertiya çand û edebiyata proleteryayê dike û vêkxistina edebî dike qada milmilane û ducemseriyeke siyasî, civakî û îdeolojîk.

\section{Li Hember Zordariya Feodalîzmê Pesindana Şoreşa Bolşevîk û Rizgarkeriya Sosyalîzmê}

Di edebiyata kurdî ya Sovyetê de ji ber nebûna çîna burjuvayê û rewşa paşdemayî ya kurdên êzîdî ducemserî di navbera sîstema feodal û sosyalîst de derdikeve holê. Ji ber vê di piraniya berhemên edebî de lêkdana edebî li ser vê milmilaneyê tê 
avakirin û piştî nîşandana wêneyê "sîstema feodal a xirabkar", Şoreşa Bolşevîk û sîstema wê ya sosyalîst wek "rizgarker" û destpêka "jiyaneke teze" tên berçavkirin.

Di yekem romana kurdî Şivanê Kurmanca de nivîskar, karekterê sereke yê romanê ku Erebê Şemo bixwe ye, yek bi yek di gundên rûm, rûs û kurdan de digerîne û dixwaze nîşan bide ku bê ciyawaziya dînî û neteweyî hemû axa, beg û dewlemendên feodal bi yek awayî serederî bi çîna hejar re dikin û zordestiya wan dirûveke sîstemîk wergirtiye. Lewra endamên malbata Ereb biçin kîjan gundî bi heman awayî bi zordestî û dilhişkiya desthilatdarên civaka feodal re rûbirû dimînin û ev kes bi azmûna jiyana xwe diselmînin ku çarenûsa hejarên mîna wan di nav vê sîstemê de her perçiqandin e. Ji ber vê dema ku agirê şoreşê tê hilkirin Ereb beşdarî hêzên şoreşgêr dibe û piştî danîna "dîwana şêwrê" (hikumeta sosyalîst a Sovyetê) dema di nav kurdan de digere li ser zimanê wan behsa xirabiya sîstema civakî û siyasî ya berê û dadperwerî û xweşiya sîstema nû dike. Nivîskar li ser zimanê Cêlo diyar dike ku bi saya "dîwana şêwrê" niha hemû mirovên "xebatçî" bi hev re dixebitin û bi saya "îngilaba Oktyabrê û dîwana şêwrê" ji "zulma patşê Nîkaleyî xûnxur, zulma bega, şêxa, axalera û mella, zulma daşnaka” (Şemo, 2009: 198) rizgar bûne.

Erebê Şemo di romana Jiyana Bextewar de jî rûdanên romanê li ser vê dubendiyê rêkdixe. Di pêşgotina romanê de diyar dike ku dixwaze bi vê romanê karîgeriya nerênî ya padîşah, axa û began li ser eşîreke kurdan berçav bike û xwînxwarî û zordariya Silêman Beg û têkiliya wî ya bi dewleta Romê re aşkera bike (Şemo, 2015: 7). Di romanê de ji bo selmandina vê angaştê rojekê milazimekî osmanî li ser navê Sultan bi mebesta amadekariya şer û berhevkirina zexîreyan ji Stenbolê tê nav eşîra sîpkan û Milazim û Silêman Beg piştî ku baceke giran davêjin ser gundiyan ji bo ku nanê Emer xwarine jê "dîş kîrasîyê" (kirêya diranan) jî werdigirin. Di encamê de endamên eşîra sîpkan bêzar dibin û biryar didin ku ji bin hukmê Osmaniyan derkevin û xwe li Rûsyayê bigirin.

Nivîskar herçend di serî de li hember Osmaniyan pesnê Rûsyayê bide jî piştî çend salan eşîra sîpkan rûbirûyê heman derdeseriyan dibe. Di xelaya 1892-1893an de gelek kesên hejar ji birçîna dimirin, lê axa û maldar her di nav xweşiyê de dijîn. Erebê Şemo ji bo berçavkirina vê rewşê diyar dike ku dema ji bo xatirê hatina Evdila Beg di mala Resûl Axa de qelî tê çêkirin li gund Çîp û Temirê şivan ji birçîna dimirin (r. 59) û gelek kesên din jî di bin deynê faîza Qelenderê dewlemend û çikûs de dinalin (r. 62). Diyar e, nivîskar herwek romana Şivanê Kurmanca di vê romanê de jî dixwaze nîşan bide ku herçend di navbera wan de guherîneke rêjeyî hebe jî sîstema feodal li hemû welatan xwedî yek wêneyî ye. Ji ber vê li ser zimanê Emer diyar dike ku padîşahê rûs jî kedxwarê çîna hejar e:

Rast e, padşayê Ûris hinek xercên zilmkarê Romê dabûn hildan behsa xeberê: dîş kiresî, qemçûr, teşîr, maledû û êd mayîn. Zor nedida Kurmancan. Padşayê Ûris jî çawa padşa ew jî kesîb ên mînanî Sertîb nikarîbûn ji bin wî xercî derketana (r. 50).

Erebê Şemo di vê romanê de di mînaka kesên ciyawaz de çendîn car bal dikêşe ser heman diyardeyê û dîmenên çewisandina çîna hejar tîne ber çavan. Bo nimûne ji ber ku Mistefa Beg kulavekî nadiyê, Îbrahîmê şivanê wî li ber sermayê nexweş dikeve û piştî demekê jî dimire. Li ser wesiyeta mêrê xwe dema Seyrana jina Îbrahîm doza heqê xwe li Mistefa Beg dike, beg wan deyndar derdixe (r. 92). Piştî 
demekê Mihemedê kurê Seyranê mezin dibe û rojekê dema bi Îsmaîlê kurê Mistefa Beg re pevdiçe Mistefa beg bi daran lê dixe û kurik di bin çovan de dikuje. Herçend komserê dewletê ji bo lêkolîna rûdanê bê gund jî Mistefa Beg wî di mala xwe de ziyafet dike û bê ku tiştek bibe meseleyê çareser dike. Bi vî awayî nivîskar di mînaka du dewletên monarşîk de nîşan dide ku beg û rayedarên dewletê hevkarên hev in û ev sîstema civaka feodal hertim dîmenên hevşêwe berhem tîne.

Bi van mînakan Erebê Şemo piştî berçavkirina wêneyê xirab ê sîstema feodal behsa pêvajoya destpêkirina Şoreşa Bolşevîk dike. Di romanê de Mistoyê ku xwediyê heman taybetmendiyên Erebê Şemo ye, dibe endamên Partiya Bolşevîk û hizrên Lenîn di nav kurd û ermeniyan de belav dike. Misto û hevalên wî yên şoreşgêr herçend li ser destê "dîwana wedelî" û hikumeta daşnakan bên êşkencekirin jî berdewam di nav gel de digerin û ji wan re diyar dikin ku "xwedîyê kesîban Lenîn e, Partîya Bolşevîkan e" (r. 126). Misto li hember zordestiya axa, rom û daşnakan hizrên Lenîn tekane rêya çareseriyê dibîne û neteweperest, dînperest $\hat{u}$ sermayedaran wek dijminê pale û gundiyan dide zanîn. Gundiyên kurd jî pêşwazî li hizrên Lenîn dikin ji ber ku di berjewendiya wan de gotiye "Xwelîyê bidine gundîyan, bibijêrin dîwana pale û gundîyan" (r. 138). Di encama romanê de piştî ku Şoreş bi ser dikeve û dawî li zordariya sîstema feodal tê "sîstemeke dadperwarane ya sosyalîst" tê damezirandin û herkes bi mafê xwe şad dibe.

Erebê Şemo di romana Hopo de herçend behsa rûdanên piştî Şoreşê bike jî bi rêya bîranînên karekterên romanê her du cîhanên dijber ên berî Şoreşê û piştî Şoreşê berawird dike. Lewra gelek caran bi rêya karekterên romanê tê bîrxistin ku kurd û ermen ji ber zordariya leşkerên Romê revîne û bi saya artêşa sor û dîwana Sovyetê hatine rizgarkirin (Şemo, 2007: 64). Her di vê çarçoveyê de Filîtê Emo wek şahidê zordariya Romê, began û daşnakan bi saya Sovyetê dibe xwedî erk û kar û bi gotina "Kî der dîwana Lênîn be, ew der wetenê min e" (r. 93) guherîna mezin a piştî Şoreşê derdibire. Her di vê çarçoveyê de Sertîpê rêvebirê kolxozê jî di mîhrîcana beranberdanê de fincana xwe ya meyê ji bo eşqa Partiya Komunîst radike ji ber ku azadî daye kurdên belengaz û bindest minetdariya xwe diyar dike. Sertîp rewşa berê û rewşa nû ji gundiyên xwe re weha berçav dike: "Sal bi sal bi dest xwe re bibînin halê xwe yê berê û halê niha. Gelo begêd me, an axayêd me, wexta ku hemû mecal di destên wan de bû, di xaniyên wiha de qe dijiyan? Komûnîstan ev yek da me.." (r. 162). Morovê katibê teşkîlata firqê jî hizrên Sertîp pesend dike û di mijara xirabiya sîstema berê û qenciya sîstema nû de dibêje:

Werin em gişk kasên xwe vexwin eşqî Partiya Lênîn, eşqî Dîwana Sovêtê, ya ku azayî da me, em ji qetla Romê xelas kirin, ji destên wan axa, beg û miftexuran, ên ku em bi hesabekî bêpere ji xwe re didane xebatê! Wan hemûyan bi teherekî em dişêlandin! Lê niha şukir hûn dibînin, em aza dijîn, êdî kesek me naşêlîne! Û niha gelek cahilêd me, ên mîna Zînê û Hesen dixebitin, çêdikin e'mrê teze, çêdikin deb û edetên teze!... (r. 259).

Heciyê Cindî jî di romana xwe ya Hewarîyê de dema bi rêya karekterên cuda cuda jiyana berî Şoreşa Bolşevîk bi bîr tîne, behsa zordariya nûnerên civaka feodal dike, bi taybetî di mînaka rûdana revandina Gulîzerê de vê diyardeyê berçavtir dike. Lewra rojekê ji eşîreta heseniyan tên Gulîzera keça Ûso dixwazin, lê Egîdê birayê Elî Axa bi vê razî nabe û dixwaze Gulîzerê birevîne. Dema Geveza xwişka Gulîzerê 
dibe asteng derbekê lê dikeve û dimire. Tevî ku keça Ûso hatiye kuştin jî tu kes hesabê wî nake û axa û begên hesenî û sîpkî di beramberî gelek diyariyan de li hev dikin û li hember kuştina keça wî tenê çar pezên kulek didene bavê Gulîzerê. Di vê rewşê de nivîskar li ser zimanê Ûso dinyayê wek "dinyaya axayan" bi nav dike (Cindî: 2008: 280) û rola wan a nerênî ya li ser civakê berçav dike.

Heciyê Cindî piştî nîşandana rewşa civaka feodal a berî Şoreşê di dawiya romanê de cih dide destpêka Şoreşê jî. Fêrîkê kurê Egîd Polatbekov wek xortekî nûgihîştî dema havînan tê gund hizrên Şoreşê di nav gundiyan de belav dike û berî ku bê kuştin bi rêya nameyekê diyar dike ku dê hikumeta Lenîn bê hewariya kesên belengaz û bi vê peyva "hewarî"yê ku navê romanê ye jî, sîstema sosyalîst a Sovyetê wek rizgarkerê çîn û komên bindest nîşan dide. Her li gor vê mizgîniyê, di dawiya romanê de leşkerên Bolşevîk Ermenistanê rizgar dikin û li vî welatî sîstema sosyalîst ava dikin (r. 400). Jixwe nivîskar jî bi boneya çil û pênc saliya avakirina hikumeta Ermenistanê ji bo derbirîna hestên xwe yên minetdariyê ev roman nivîsiye û xwestiye di çarçoveya berawirdkirina jiyana berî Şoreşê û piştî Şoreşê de dadperweriya sîstema sosyalîst bipeyîtîne.

Bi van mînakan di romanên her du nivîskaran de jî feodalîzm bi mekanîzmayên xwe yên civakî û siyasî wek sîstemeke serkutker û xirabkar tê berçavkirin ku ji bilî zordarî û nexweşiyê tu tiştekî nayîne holê. Li hember vê, Şoreşa Bolşevîk wek rizgarker digihîje hewariya çîna karker û bi danîna sîstema sosyalîst a Sovyetê hemû mafên zeftkirî yên hejaran li wan vedigerîne û dadperwerî û wekheviya civakî pêk tîne.

\section{Di Mînaka "Qelen" û "Şilet"ê de li Hember Adetên Xirab ên Feodalîzmê Pesindana Azadîxwaziya Sosyalîzma Sovyetê}

Di çarçoveya çêkirina ducemseriya feodalîzm û sosyalîzmê de di romanên kurdî yên Sovyetê de ne tenê du sîstemên civakî û siyasî yên dijber tên berawirdkirin, di heman demê de du çand û awayên jiyanê jî tên berawirdkirin ku yek ji wan bi reşbîniyeke tîr û tarî tê nîşandan ya din jî bi geşbîniyeke bihiştî tê berçavkirin. Lewra li gor riwangeha pêşengên realîzma sosyalîst, diviyabû nivîskar erka bicihkirina bernameya damezirandinê ya sîstema Sovyetê hilgirta û pûçî û şaşiyên çanda berê nîşan bida. Ev ji bo nîşandana rûyê modern û pêşketinxwaz ê sosyalîzmê tiştekî pêwîst bû ku bi vê rêkê karektera mirovperwer, pêşketinxwaz û azadîxwaz a sîstema Sovyetê dihat nîşandan. Her di vê çarçoveyê de di edebiyata kurdî ya Sovyetê de mijara qelen û şiletê di berawirdkirina adetên xirab ên feodalîzm û azadîxwaziya sosyalîzmê de wek mijareke berbelav û populer derdikeve pêş.

Di romana Şivanê Kurmanca de dema Ereb diçe mala Sefoyê mêrê meta xwe dil berdide Karêya keça wî, lê Sefo weku pêşmerc doza qelen lê dike. Ereb demeke dirêj kar dike da ku qelenê xwe temam bike, lê Sefo piştî wergirtina gelek pereyan bêbextî li Ereb dike û keçikê nadiyê. Li ser vê Ereb, Sefo dikuje û bê ku bi Karê re bizewice ji wî gundî derdikeve (r. 130). Ev rûdan nîşan dide ku wek adeteke xirab a civaka feodal qelen dibe serçaviya bêrewiştî û bextreşiya mirovan û sedema berdewamiya newekheviya regezî.

Di romana Jiyana Bextewar de sîstema zewacê ya civaka feodal di şêweyeke kolekirinê de tê berçavkirin ku rola xulamtiyê bi ser jinê de disepîne. Her di vê çarçoveyê de Xezal dema Cemîleya keça xwe derbarê zewacê de şîret dike kodên vê sîstema koletiyê weha berçav dike: 
Çi bi serê te biqewime tu bi kesî re xeber nadî. Di malan de timê zarêd biçûk hene, tu gerek ê her bi wan re xeber bidî, çi ji te re lazim e bibêjî wan, ew ê bibêjine xwesîya te, an xezûrê te, xulese heke tu dixwazî tiştekî ji wan bipirsî. Ji wê bi şûn de, lawo, wekî tu heft rojan bê nan û av bî, birçînan bimirî jî tu gerek ê dengê xwe nekî. Sibeyê şeveqê tu gerek ê berî gişkan rabî, serçavê xwe bişoyî, derê malê paqij bikî, destşo, sabûn û pêşgîrê hazir bikî, bisekinî heta kalemêrê xwezûrê te radibe, hema ku ew rabû, midasê wî li ber bigirî, kincên wî bigirî, wekî ew li xwe bike. Taştêya wî li ber daynî, lê her gav wexta ew nan dixwe tu gerek ê tasek av li ber daynî, paşê herî şixulê malê bikî (r. 47).

Erebê Şemo di romana Hopo de digel ku behsa rûdanên piştî Şoreşê jî dike bal dikêşe ser berdewamiya karîgeriya nerênî ya adetên berê û li dor jiyana Zînê û Zelêxê behsa nerîta qelen dike. Di romanê de Hesen bi mebesta dîtina Zînê diçe gundê wê, Zînê herçend bi hatina wî kêfxweş bibe jî ji ber guvaşa adetên civakî nikare vê kêfxweşiya xwe nîşan bide û di wextekî kin de rakirina "edetên sal û zemanan" zehmet dizane. Lê Hesen bi berdevkiya têgihiştina nû diyar dike ku divê xortên mîna wan adetên kevin rakin (r. 83) û bingehên jiyana nû bihêztir bikin. Nivîskar tevî rastdêrana hizra Hesen diyar dike ku ji ber vê rûdanê hin gundiyên nûnerê çanda berê Zînê bi bênamûsiyê tawanbar dikin û derheqê wê de gotinên xirab belav dikin. Digel vê xirabkariyê Zînê geşbîn e ku "zû be dereng be, ew edetên kevin wê bêne hildan" (r. 88).

Her li ser mijara dijayetiya qelen di romanê de çîroka Zelêx û Sadiqê mêrê wê jî tê veguhestin ku dema Zelêx dixwaze bi Sadiq re bizewice malbata wê hewl dide bi qelenekî zêde wê bidin kesekî din. Digel vê Sadiq û Zelêx dizewicin û kurekî wan çê dibe. Piştî demekê Sadiq dimire, vê carê bavê Zelêxê dil dike wê bi qelen bide mêrekî din, lê Zelêx ji ber hebûna manewî ya Sovyetê xwe bihêz dizane û vê qebûl nake (r. 124). Ji ber vê serboriyê Zelêx dema Zîna keça xwe dide Hesen û pirsa qelen jê tê kirin dana qelen wek "alçaxiyeke mezin" dibîne û bidawîhatina vê adeta xirab radigihîne (r. 248). Jinên pîr herçend nedana qelen tiştekî xirab bizanin jî wek nûnerên nifşa piştî Şoreşê nikarin tu karîgeriyekê li ser Zelêx û Zînê çê bikin. Loma jî Hesen û Zînê bi saya sîstema sosyalîst a Sovyetê bê qelen û kêşeyeke mezin dizewicin û di romanê de zewaca wan wek serkeftineke jiyana nû tê nîşandan.

Di Hewarîya Heciyê Cindî de mijara zewacê di çarçoveya dijayetiya adeteke dînî ya kurdên êzîdî de tê rojevê ku ew jî herambûna zewaca kesekî êzîdî ye bi kesekî ne êzîdî re. Di romanê de piştî ku Egîd ji bo Sîbîrê tê mişextkirin û ji xizmên xwe dûr dikeve ji ber qencî û xwedîderketina wê bi jineke rûs re dizewice û sê zarokên wan çê dibin. Piştî çend salan dema Elî Axayê birayê Egîd tê mala birayê xwe û dibîne ku birayê wî gunehê "şilet"ê kiriye û adeteke wan a berê binpê kiriye gelek aciz dibe. Herçend Elî Axa ji ber dûrketina bi salan û hestên biratiyê vê rûdanê zêde mezin neke jî piştî ku Egîd tevî jina xwe û zarokên xwe tên gund, guvaşa civakî û dînî dest pê dike. Gundiyên wan ji ber ku birayê axa ye nerazîbûna xwe bi aşkera nebêjin jî vê rewşê baş nabînin û ji ber gunehê "şilet"ê gundî hew tên mala wan. Di ser de qewal jî ji çiyayê Şengalê tên gundê wan, lê wek cezayeke manewî naçin mala axa û nerazîbûna xwe diyar dikin (r. 342). Okiz herçend hewl dide qewalan bi vê zewacê razî bike jî pêşniyaza wî nayê pejirandin. Di encamê de ji ber zexta dînî Egîd ji neçarî biryar dide ku jineke êzîdî di ser Annayê de bîne û bi vê kiryara xwe 
dibe sedem ku Annaya jina wî ji gund biçe û piştî demeke kurt jî ji xeman bimire. Li hember vê piştî Şoreşê ev têgihîştina şaş diguhere û di mijara zewacê de mirov bi serê xwe biryar didin. Bo nimûne Nûrêya keça Egîd dema dibe rêvebira sêwîxaneyê gelek xort li dora wê digerin, lê kes wek berê ne dikare wê birevîne ne jî guvaşeke civakî li ser çê bike. Loma jî bi dilê xwe xortekî diecibîne û pê re dizewice.

Bi van mînakan Erebê Şemo û Heciyê Cindî qelen û şiletê ji bo nîşandana adetên xirab ên feodalîzmê bi kar tînin û azadiya zewacê û vîna hilbijartina takekesî jî wek taybetiya sîstema sosyalîst a Sovyetê derdixin pêş. Ji ber vê her du nivîskar dema behsa jiyana berî Şoreşê dikin qelen û şilet hertim dibin sedema bextreşiya karekterên edebî, lê dema behsa rûdanên piştî Şoreşê dikin ev astengî ji holê radibin û digel kêşeyên biçûk ên nûnerên civaka feodal nifşên "jiyana teze" bi vîna xwe ya azad hevjînên xwe diyar dikin.

\section{Li Hember Nezaniya Serdema Feodal Xwendewarî û Ronakgeriya Sosyalîzma Sovyetê}

Nezanî û xwendewarî di berawirdkirina reşbîniya serdema feodal û geşbîniya sîstema sosyalîst de wek mijareke ducemseriya romanên kurdî yên Sovyetê xwedî cihekî girîng e. Lewra di serdema serweriya feodalîzmê de derfetên xwendin û hişyariya çîna hejar gelek sînordar in û di nav kurdên êzîdî de jî ji ber baweriya dînî ya qedexebûna xwendinê ev derfet qet nînin. Bi danîna sîstema Sovyetê ev rewş diguhere $\hat{u}$ ji rencber, şivan û berdestiyên civaka feodal kesên zana, xwenda $\hat{u}$ pêşketî peyda dibin. Di romanên Erebê Şemo û Heciyê Cindî de li dor vê berawirdkirinê sîstema sosyalîst a Sovyetê wek projeyeke ronakgeriya modern tê pêşkêşkirin ku civakeke pêşmodern vediguherîne ser civakeke modern.

Di Şivanê Kurmanca de dema zarokên hevtemen ên Ereb di xwendingehê de dixwînin Ereb wek kurê malbateke xizan xizmeta wan dike û ji xwendinê bêpar dimîne. Dema dilê mamosteya gund pê dişewite û piştî temamkirina kar wî jî dike nav xwendekaran, vê carê jî ji ber ku cilên wî qetandî ne, zarokên meleganan tinazên xwe pê dikin (r. 88) û pê re hevaltî nakin. Nivîskar bi vê dîmenê nîşan dide ku mîna hemû warên newekheviya çînî, di warê xwendinê de jî çîna hejar hatiye paşguhxistin û rêya zanîn û xwendinê li wan hatiye girtin.

Ji bilî serdestî û bindestiya çînî Erebê Şemo di Jiyana Bextewar de bal dikêşe ser têgihîştina gunehbûna xwendinê ya êzîdiyan û di kesayeta Emerîk û Sehîdê kurê wî de vê baweriyê dide ber lêpirsînê. Emerîk gava di serdema menşevîkan de li Tiflîsê dixwaze Sehîdê kurê xwe bide xwendinê nebûna pere û herambûna xwendinê wek astengî derdikevin pêşiya wî, lê piştî ku Tiflîs dikeve destê Artêşa Sor ev astengî ji holê radibin û li her derê welat ji bo her miletî xwendingeh tên vekirin. Li ser vê bingehê Sehîd jî dest bi xwendinê dike û gotinên şêxan ên sebaret bi herambûna xwendinê wek "giliyên derew" li qelem dide (r. 207).

Nivîskar di mînaka Sehîd de çîroka pêgihandina xortekî kurd vedigêre ku bi saya Şoreşê mirovekî serkeftî jê derdikeve. Mistoyê ku di romanê de nûnertiya Erebê Şemo dike di kesayeta Sehîd de vê serkeftinê bi Sovyetê ve girê dide û dibêje: "Wekî Lenîn-Partîya Bolşevîkan nebûya, gelo kê yê îzin bida ewladê Kurdan ê kesîb, wekî bê bajarê padşê û bêpere, bi kincên rind û xwarina baş bixwe û hîn bibe" (r. 222). Sehîd wek berê (semere) sîstema Sovyetê, di 1932yan de li enstîtûya Lenîngradê bi awayekî serkeftî dersên xwe temam dike û berê xwe dide gundê xwe. 
Di trênê de dema rêwiyekî kal hîn dibe ku Sehîd kurd e bawer nake ku kurdekî ew çend pêş ketibe (r. 224) û bi vê şaşmayînê nivîskar careke din amaje bi pêşketinxwaziya sîstema Sovyetê û Partîya Bolşevîk dike.

Erebê Şemo ji bilî ku di kesayeta Sehîd de behsa pêşketinên warê xwendinê dike, di heman demê de ji bo diyar bike ku bingeha xwendinê di nav kurdan de piştî Şoreşê ji aliyê Sovyetê ve hatiye danîn di romanê de cih dide hin zanyariyên rasteqîne jî ku di vê serdemê de kurdên Sovyetê cara pêşî bi alfabeya Hakop Xazaryan (Lazo) û pirtûka wî ya Şemsê dest bi xwendina kurdî dikin (209), paşê jî Misto (Erebê Şemo) li ser alfabeya kurdî dixebite da ku "gilîyên Lenîn û zanebûna marksîzmê - Lenînîzmê" (r. 221) di nav kurdan de belav bike. Loma jî Misto wek endamê Komîteya Merkezî ya Partiya Bolşevîkan a Ermenistanê di sala 1927an de bi mebesta pêgihandina kadroyên kurdan diçe Moskovayê cem Stalîn û vê mijarê pê re diaxive. Li ser vê Partî di sala 1927an de ji bo kurdan "texnîkûma pêdagogîyê" vedike û bi vî karî bingeha xwendin û pêşketinê di nav kurdan de datîne.

Mijara ronakgeriya Sovyetê di romana Hopo de li dor jiyana Zînê tê behskirin û di kesayeta keçeke kurd de asta pêşketina xwendewariya Sovyetê tê berçavkirin. Zînê tevî qedexeya xwendinê ya êzîdiyan bi saya dezgehên sîstema Sovyetê dixwîne û piştî temamkirina xwendina xwe li gundê xwe dest bi xebatê dike. Wek keçeke xwendewar di kitêbxaneya wê de berhemên Hovhannês Tûmanyan, Êgîşê Çarêns, Pûşkîn, Tolstoy, Tûrgenyev û ji kitêbên kurdî jî Emrê Lenîn, Kurdêd Elegezê, Şivanê Kurd û Koçekê Derewîn hene.

Di romana Hopo de ji bo nîşandana pêşketina asta civaka êzîdî tê diyarkirin ku gundiyên kolxozvan di klûba gund de rojnameya Riya Teze dixwînin û guhdariya radyoya kurdî dikin. Dema di radyoyê de derbarê rewşa hewayê de agahiyeke zanistî tê dayîn bi mebesta berawirdiya nezaniya berê û pêşketina zanistî ya Sovyetê zilamekî kal dibêje:

Ê wekî ev bager beriya Dîwana Sovêtiyê biqewimiya, gelo me yê çi bikira? Em ê biçûna cem faldaran, an jî cem mele û şêxan çika ew çi dibêjine me. Wan ê bigotana: "Herin qurbanan bidin, pêz ser jê bikin, çiralixan bidin, me jî ji bîr mekin (r. 39).

Dîsa li dor mijara rewşa hewayê zilamekî kal diyar dike ku neviyê wî li Erîvanê xwendekar e, gotiye di kitêbekê de xwendiye ku dê rewşa hewayê biguhere, lê kalekî din wek nûnerê nezaniya berê diyar dike ku neviyê wî kesekî derewîn e. Li hember vê dijayetiyê wê şevê berf dibare û nivîskar zanista ku bi saya Sovyetê di nav xelkê de belav bûye rast didêrîne. Bi vî awayî nivîskar di mînaka zanîna rewşa hewayê de li hember nezaniya serdema berê pesnê ronakgeriya serdema Sovyetê dide û vê hişyariyê bi dezgehên Sovyetê ve girê dide.

Di Hewarîyê de ji bo nîşandana nebûna xwendewariyê ya berî Şoreşê tê diyarkirin ku dema Elî Axa piştî deh salan saloxê Egîdê birayê xwe werdigire û dil dike biçe dîtina wî, nexwendewarî wek kêşeyeke mezin derdikeve pêşiya wî. Lewra di gundê wan de ne xwendingeh heye ne jî kesekî xwenda heye ku arîkariya wî bike. Di dawiyê de ji bo ku bikare arîkariya wî bike ji gundê Poştê gazî Qanatê Nadir dikin ku "bi zora rûyê xwe çûye xwendiye" (r. 314) û xwe fêrî zimanê rûsî kiriye. Li ser vê Elî Axa li hember gelek diyariyan Qanat vedixwîne û bi arîkariya wî xwe digihîne Sîbîryayê. Piştî ku Elî Axa diçe Sîbîryayê û vedigere êdî bi rêya nameyan 
bi birayê xwe re peywendî datîne û gundiyên Dîgorê jî bi vê boneyê yekem car name dibînin (r. 330).

Li hember vê rewşa paşketî ya feodalîzmê di pêvajoya Şoreşê de Fêrîkê kurê Egîd di bin karîgeriya hizrên Şoreşê de li gund pirtûkên Belînskî, Çernişevskî, Dobrolyûbov û Gorkî dixwîne (r. 361). Li hember rewşa paşketî ya berê piştî damezirandina sîstema Sovyetê êdî li hemû gundan xwendingeh tên vekirin û zarok tên perwerdekirin. Romiyê Heso di gundê Kûrekendê de zimanê rûsî hînî "kur û keçên teze rabûyî” dike û pirtûkên Pûşkîn, Tolstoy, Gorkî û Şoloxov bi wan dide xwendin. Bi vî awayî di bin ronakgeriya çandî ya Sovyetê de li vî gundî tu kesekî nexwenda namîne. Loma jî vegêr li ser zimanê Reşîd radigihîne ku hikumeta Sovyetê "her mecal û mekan" dane wan ji bo "bipêşdeçûn û zanebûnê" (r. 35).

Di Hewarîyê de bi rêya diyaloga navbera vegêr û Moskov behsa zarokên kurd ên sêwîxaneyê jî tê kirin ku bi saya Dîwana Sovyetê hatine rizgarkirin û niha bi xwendin û zanyarî gihîștine cihên bilind û xizmeta çand û edebiyata kurdên Sovyetê dikin. Vegêr bi gotina "Dîwana me per û bask da wan û hezaran hezarên mîna wan bi firê xist” (r. 43) careke din ronakgerî û pêşketinxwaziya Sovyetê dupat dike û bi minet yada vê qenciyê dike.

Mîna Erebê Şemo Heciyê Cindî jî di romana xwe de behsa destpêk û bingehdanîna xwendinê dike di nav kurdên Sovyetê de û di vê mijarê de xebatên Lazo bi bîr tîne. Bi vegêrana Moskov û li ser zimanê Lazo tê ragihandin ku Dîwana Sovyetê ji bo ku li ser tîpên ermenîkî ji kurdên komara Ermenistanê re alfabeyekê dayne Lazo radispêre, ew jî şev û roj dixebite û pirtûka Şemsê amade dike, lê ev bi gotina Lazo ji ked û xêrxwaziya wî bêtir bi saya "mecal û mekanê Dîwana Sovyetê" pêk tê (r. 48).

Erebê Şemo û Heciyê Cindî di mînaka van rûdanan de û bi serboriya karekterên ciyawaz diyar dikin ku feodalîzm û mekanîzmayên wê yên civakî, siyasî û dînî, nezanî berhem aniye û sîstema sosyalîst a Sovyetê jî bûye afirîner û belavkerê xwendewarî û ronakgeriya modern. Loma jî di wênekirina jiyana feodal a van romanan de nezanî û nexwendewarî wek çavkaniyeke reşbîniya feodalîzmê li pêşiya hişyarî û pêşketinê dibe asteng, lê piştî Şoreşê bi rexsandina derfetên xwendin û pêşketinê nifşên nû di nav ronakgeriyeke sosyalîst de tên perwerdekirin û bi enerjiyeke zêde hewla hişyarkirin û pêşxistina civaka xwe didin.

\section{Li Hember Paşdemayîna Feodalîzmê Pêşketina Aboriya Sosyalîzma Sovyetê}

Rewşa aborî ya sîstema feodal û sîstema sosyalîst yek ji mijarên sereke yên ducemseriya romanên kurdî yên Sovyetê ye. Herwek nêrîna îdeolojiya Sovyetê di civakên feodal de keda mirovên çîna hejar ji aliyê çînên serdest ve tê talankirin û koletiya axa û began û padîşahan bi ser wan de tê sepandin. Li hember vê bi damezirandina sîstema sosyalîzmê di çarçoveya xebata kolektîf a kolxozan de herkes di beramberî keda xwe de dibe xwedî heq û dawî li mêtinkariya beg û axayan tê.

Di romana Şivanê Kurmanca de di mînaka malbata Erebê Şemo de bêtir behsa jiyana paşdemayî û trajîk a çîna hejar tê kirin. Malbata Ereb dema li gundê Azatê dimînin ji ber nebûna dewarên wan û sergînên hişkkirî zivistanê nikarin xwe germ bikin. Loma jî diya Ereb ji axa lava dike ku bihêle zarokên wê xwe di tewleya heywanan de germ bikin. Axa bi merca ku zarok di tewleyê de xizmeta heywanên 
wî bikin vê dipejirîne û zarok heta êvarê li "ber afirê hespa, gamêşa, û dewarê mayîn, notla pepûka, tî, birçî" dixebitin heta ku diya wan karê malê temam dike (r. 56).

Di romanê de malbata Ereb û kesên mîna wan hertim xulamtî û şivantiya dewlemendan dikin û rastî tundûtûjiya wan tên. Loma jî li gundê Alêksandrovskê gelek caran şivan û gavan ji ber lêdanên meleganan nexweş dikevin û dimirin (r. 64). Herweha dema gur dikeve nav keriya Ereb û bizina axayekî birîndar dike heman aqîbet tê serê wî jî. Di encamê de Ereb hem lêdan dixwe hem jî ji heqê xwe yê salê mehrûm dimîne. Loma jî mecbûr dimîne ji bo peydakirina nanê zivistanê heta biharê bi nanozikotî xulamtiya axeyekî din bike. Nivîskar ji bo nîşan bide ku di nav sîstemeke civakî ya weha de mirovên hejar ji pêşketinên herî seretayî yên şaristaniyê jî mehrûm in diyar dike ku dema Ereb bi mebesta birina nameyekê diçe Qersê li wir ji bo ku pê nan bixwe kevçî, kêr û çetel didine ber, lê ji ber ku nizane kêr û çetel bi kêrî çi tên wan wek diyarî û pêlîstok davêje bêrîka xwe û ji ber vê kiryara xwe jî bi diziyê tê tawanbarkirin (r. 81).

Li hember vê rewşa paşdemayî ya sîstema feodal di romana Jiyana Bextewar de pêşketinên aborî yên piştî Sovyetê tên berçavkirin. Ji ber ku îmtiyaz û milkiyeta axa û began li ser axê nemaye û wek sîstema karê kolektîf li gundan kolxoz tên avakirin herkes bi wekhevî ji dahata kolxozan sûd werdigire. Sehîd ji bo pêşvebirina dahata kolxoza gund digel gundê Camûşvanayê "leca sosyalîstiyê" li dar dixe û bi vî awayî hewl dide dahata gundê xwe û aboriya welat pêşve bibe. Li hember vê hemû kolxozvan şahî dikin û memnûniyeta xwe ya jiyanê derdibirin.

Di serdema Sovyetê de berevajî dîmenên trajîk ên jiyana serdema feodal wek nîşaneya pêşketina sîstema aborî ya Sovyetê ji malan dengê stranên radyoyê tê bihîstin û hemû malên gundan bi ronîya elektirîkê şemal didin. Di vê çarçoveyê de Sehîd ji bo avadankirina gundê xwe derbarê av, elektirîk û avakirina xaniyên xweş dikeve nav hewldanan û ji bo nîşandana minetkariya xwe li hember van pêşketinan di Sibata 1939an de dema li Moskovayê "qurilta 18'an a Partîya Komunîstan" dicive digel hevalên xwe li serê çiyayê Elegezê bûsta Lenîn çê dikin (r. 248) û xweşhaliya xwe ji ber van pêşketinan bi rêya sembolîzasyona vê bustê diyar dikin.

Di romana Hopo de jî pêşketina sîstema aborî ya Sovyetê bi rêya kolxozê tê berçavkirin. Sertîpê berpirsyarê kolxozê bi şev û roj karûbarê kolxozê dişopîne. Dema nîvê şevê diçe tewleyê û bi elektirîka îlyîç tewleyê mîna rojê ronî dike kêfxweşiya xwe bi van gotinan derdibire:

Beriya Dîwana Sovêtiyê ronahiya wiha di malên Kurdan de tunebû. Lempeyên niftê jî, di mala hemû kesî de tunebûn. Di malan de, çirayêd niftê vêdixistin, an çiralixêd ji donê bizinan. Ew jî, hemangî birûsî didan. Lê gava ku mirov sibehtirê radibû, ber bêvilêd mirovan bi teniyê reş dikirin (r. 20).

Ji ber vê, di gund de herkes bi dil û can dixebite û ji bo pêşvebirina bingeha aborî ya welat kar dike.

Herwek Sertîp Sehîdê katibê firqê jî wek nûnerekî sîstema Sovyetê ji bo pêşvebirina aborî ya gundê xwe çend xortên gund dişîne nehiyê da ku qursa "kombaynçiyan û traktorîstan" wergirin. Li ser vê Egîd, Lûlo, Îsko û Cimo tên şandin û ji bo vê rûdanê li ser zimanê kalekî tê ragihandin ku eger partiya Lenîn nebûya dê tu carî xortên 
kurd hînî bikaranîna makîneyên weha nebûna û dê hîna jî bi ga, hesp û deveyan emel bikirana (r. 27). Ji ber vê dema her çar xort bi makîneyên xwe ve tên gund hemû gundî dikin şahî û diçin pêşiya wan.

Wek nûnereke sîstema nû ya Sovyetê Zînêya agronom (endazyara kiştûkal) a gund jî di pêşvebirina aboriya gund de bi awayekî çalak beşdarî dike û bi taybetî di çandin û zêdekirina genimê kûbanê de serkeftineke mezin bi dest dixe. Dema Profesor Xaçatriyan ji bo sihêtiya genimê kûbanê tê gund û pîrozbahî li Zînê dike Sehîd di çarçoveya berawirdkirina rewşa niha û ya borî de vê pêşketinê bi Sovyetê ve girê dide: "Xaniyêd me yên berê binerd bûn, lê bi saya Dîwana Sovêtiyê em ji binê erdê derketin roniyê" (r. 107). Zînê jî dema di nav genim de digere gotinên pîra xwe bi bîr tîne ku berê kesên xizan nikaribûn nan peyda bikin, li ber deriyê dewlemend û began digeriyan û eger wan deyn jî bida faîzeke giran dida ser pişta gundiyan (r. 111-112). Ji bo berawirdkirina rewşa aboriya niha û berê li ser zimanê pîra Zînê rûdana Mirad Axa û kalê Zînê tê veguhestin, zilm û zordariya axayan tê bîrxistin û tê gotin ku bi saya Lenîn niha di rewşeke gelek baş de ne (r. 114).

Herwek romana Jiyana Bextewar di romana Hopo de jî behsa "leca sosyalîstiyê" tê kirin ku mebest jê handan û pêşvebirina bingeha aboriya welat e. Sertîb tevî çend kolxozvanên xwe yên jêhatî û Zînê ji bo girêdana "leca sosyalîstiyê" diçin gundê cîran û bi dahol û zirneyan dikevin nav gund. Her du kom di klûba gund de rûbirûyê hev dibin û ji ber xebat û jêhatîbûna wan gundê Zînê bi ser dikeve.

Di Hewarîya Heciyê Cindî de ev mijar di mînaka gundê Kûrekendê de tê behskirin û ji aliyê pêşketina aborî ve di navbera serdema berî Şoreşê û sîstema Sovyetê de berawirdî tê kirin. Kûrekendê berî şoreşê gundekî kavil e, lê bi hatina hikumeta Sovyetê gund tê şênkirin û ji her aliyî ve tê avakirin. Loma jî Kûrekendê bi şev bi "lempeyên Îlyîç" şemal dide û dengê radyoya kurdî ji kuçeyên wê hildibe (r. 44, 171). Mîna romanên Erebê Şemo di vê romanê de jî hebûna kolxozê wek pêşketinekê tê berçavkirin, lewra hemû kûrekendî di kolxozê de kar dikin û gelek berhemên mîna pembû, tirî û pincarê hiltînin. Nivîskar di çarçoveya çêkirina geşbîniya sîstema Sovyetê de vê pêşketinê bi van gotinan romantîze dike: "Xweliya deşta Yêrêvanê ya tev de zêr bi xebatkarên xwe yên teze re gul vedide, dixemile, bi gûşiyên tiriyên şêrîn î cinetî, bi hezar turletehmî..." (r. 34).

Bi van mînakan di romanên navborî de dema behsa rûdanên berî Şoreşê tê kirin hertim dîmenên paşdemayî û trajîk ên mirovên çîna hejar tên berçavkirin û ev paşdemayîn jî bi sîstema aborî ya civaka feodal ve tê girêdan, lê bi damezirandina sîstema sosyalîst a Sovyetê mîna warên din di warê aborî de jî pêşketineke berbiçav çê dibe. Di romanên Erebê Şemo û Heciyê Cindî de damezirandina kolxozan, lembeyên Îlyîç, radyo û bikaranîna makîneyên nû yên berhemanînê wek destkeftiyên sîstema sosyalîst tên romantîzekirin û di çarçoveya ducemseriya aboriya paşdemayî ya feodalîzm û aboriya pêşketî ya sosyalîzmê de careke din pesnê Sovyetê tê dayîn û erka bernameya damezirandinê tê bicihanîn.

\section{Encam}

Realîzma sosyalîst wek teoriyeke edebî ya îdeolojîk ji ber taybetmendiya xwe ya îdeolojîk xwe dispêre rêbazeke taybet ku ew jî berawirdkirin û çêkirina ducemseriyekê ye. Di vê rêbazê de li hember ruxsarê naverok, li hember nirxa 
estetîk nirxa civakî, li hember takekes civak, li hember bohemîzm û mîstîsîzmê afirandin û berhemanîn, li hember çîna feodal û burjuva çîna proleter wek cemsereke alternatîf tê danîn û ji edebiyatvanan tê xwestin ku cemsera dijber pûç bikin û cemsera alternatîf jî îdealîze bikin.

Di romanên her du pêşengên edebiyata kurdî ya Sovyetê de li gor berçavgirtina rewşa civakî ya kurdên êzîdî di çarçoveya bernameya damezirandinê de li hember çand û sîstema feodal hewla binecihkirina sîstema sosyalîst tê dayîn û romanên navborî li ser vê berawirdkirinê tên avakirin. Di vê berawirdkirinê de nivîskarên kurd ji ber pêgîrbûna xwe ya bi sosyalîzma Sovyetê her du sîstemên civakî û siyasî di nav reşûspîtiyeke yekalî de berçav dikin û romanên xwe rasterast dikin qada propagandaya îdeolojiya Sovyetê. Ev jî nîşan dide ku ev roman li ser tezekê hatine nivîsîn û xizmeta rastdêrana îdeolojî û siyaseteke diyarkirî dikin.

Ji ber vê çendê romannûsên kurd dema behsa jiyana berî Şoreşa Bolşevîk dikin hertim berê xwe didin rûdan û karekterên negatîf û sîstema feodal bi wêneyên dojehî berçav dikin. Di vê cîhanê de beg, axa, zilamên dînî û rayedarên dewletên monarşîk bi awayekî dilhişkane endamên çîna hejar diçewsînin û dest datînin ser mal û milkê wan, lê dema Şoreşa Bolşevîk bi ser dikeve hemû hêzên serkutker tên jinavbirin û jiyaneke dadperwer a bihîştî tê avakirin. Loma jî Şoreşa Bolşevîk di romanên navborî de wek rizgarkerê kurdên hejar bi germî tê pêşwazîkirin û pêşengê Şoreşê jî wek mirovên pîroz tên pesinandin.

Bêguman di van romanan de berawirdkariya "dojeha feodalîzm" û "bihișta sosyalîzmê" ne tenê bi guherîna sîstema hikumdariyê bi çand û ronakgeriya xwe jî tê berçavkirin. Di cîhana feodal de bi rêya adetên xirab ên mîna qelen û şiletê pêşî li azadiya mirovan tê girtin, lê sosyalîzm di şûna van adetên xirab de azadiyê tîne, di serdema feodal de xwendin û zanyarî nîne û heram e, lê sosyalîzma Sovyetê bê ciyawaziya etnîk bi rêya dezgehên dewletê komên etnîk ên mîna kurdên êzîdî perwerde dike û ji mirovên nezan karekterên ronakger pêdigihîne. Herî dawî di serdema feodal de xelk di rewşeke paşdemayî de dijîn, lê bi saya sîstema sosyalîst a Sovyetê mirovên belengaz di kolxozan de karên hevbeş dikin, ji teknolojiya pêşketî sûd werdigirin û ji her aliyî ve qalîteya jiyana wan bilind dibe. Bi vî awayî nivîskarên kurd bi hestên minetdariyê berê xwe didin Sovyetê û pêgîrbûna xwe di asta herî bilind de derdibirin.

\section{Çavkanî}

BOYÎK, Eskerê (2004). Nûra Elegezê. Oldenburg: Weşangeha Dengê Êzîdiyan.

CINDÎ, Heciyê (2008 ). Hewarî. Diyarbakır: Lîs.

FREVILLE, Jean (1999). Plehanov ve Toplum, Sanat, Estetik, Eleştiri. (A. Bezirci, Wer.). Toplum, Sanat, Eleştiri. İstanbul: Evrensel Basım Yayın.

GORKİ, M. (2009). M. Gorki'nin 17 Ağustos 1934 Tarihindeki Sovyet Yazarlar Birliği Birinci Kongresinde Sunduğu Bildiri. M. Öcal-S. Gürçayır-S. Çalış (Amadekar), Y. Özer (Wer.), Halk Bilimde Kuramlar ve Yaklaşımlar (3). Ankara: Geleneksel Yayıncılık.

İDİL, A. Mümtaz (1983). Sovyet Romanı. Ankara: Yarın Yayınları. 
JDANOV, A. A. (1996). Edebiyat Müzik ve Felsefe Üzerine (Çapa Duyem) (F. Berktay, Wer.). İstanbul: Kaynak Yayınları.

KURTULUŞ, Akif (1996). Politika ve Sanat, Ekim Devrimi (1917-1932) (Çapa Yekem). İstanbul: Avesta Yayınları.

LUNAÇARSKİ, Anatoli (2000). Devrim ve Sanat (S. Kaya, Wer.). Ankara: İnter Yayınları.

MARX-ENGELS-LENIN (2006). Sanat ve Edebiyat (Çapa Duyem) (A. Çalışlar). İstanbul: Evrensel Basım Yayın.

PLEHANOV, Georgi V. (1999). Toplum, Sanat, Eleştiri (Çapa Yekem) (A. Bezirci, Wer.). İstanbul: Evrensel Basım Yayın.

PLÎXANOF (2005). Huner î Jiyanî Komelayetî (Çapî Yekem) (H. K. Arif, Wer.). Hewlêr: Dezgay Çap û Billawkirdnewey Mukriyan.

OKTAY, Ahmet (2008). Toplumcu Gerçekçiliğin Kaynakları (Çapa Çarem). İstanbul: İthaki Yayınları.

ŞAN, Mustafa Kemal (2012). Edebiyat Sosyolojisinin Tarihinden Basamaklar. (Çapa Sêyem) K. Alver (Ed.), Edebiyat Sosyolojisi. Ankara: Editör: Köksal Alver, Hece Yayınları.

ŞEMO, Erebê (2015). Jîyana Bextewar. Diyarbakır: Lîs.

ŞEMO, Erebê (2007). Hopo. Diyarbakır: Lîs.

ŞEMO, Erebê (2009). Şivanê Kurmanca. M. Aydogan (Amadekar). Diyarbakır: Lîs. 